\title{
Functional Recovery after Peripheral Nerve Injury is Dependent on the Pro-Inflammatory Cytokines IL-1 $\beta$ and TNF: Implications for Neuropathic Pain
}

\author{
Sylvain Nadeau, ${ }^{1}$ Mohammed Filali, ${ }^{1 *}$ Ji Zhang, ${ }^{2 *}$ Bradley J. Kerr, ${ }^{3}$ Serge Rivest, ${ }^{1}$ Denis Soulet, ${ }^{1}$ Yoichiro Iwakura, ${ }^{4}$ \\ Juan Pablo de Rivero Vaccari, ${ }^{5}$ Robert W. Keane, ${ }^{6}$ and Steve Lacroix ${ }^{1}$ \\ ${ }^{1}$ Centre de recherche du Centre hospitalier de l'Université Laval and Department of Molecular Medicine, Université Laval, Québec, G1V 4G2, Canada, ${ }^{2}$ The \\ Alan Edwards Center for Research on Pain, McGill University, Montréal, Québec, H3A 2B2, Canada, ${ }^{3}$ Centre for Neuroscience, University of Alberta, \\ Edmonton, Alberta, T6G 2G3, Canada, ${ }^{4}$ Center for Experimental Medicine and Systems Biology, Institute of Medical Science, University of Tokyo, Tokyo \\ 108-8639, Japan, ${ }^{5}$ Department of Neurological Surgery and the Miami Project to Cure Paralysis, and ${ }^{6}$ Department of Physiology \& Biophysics, University of \\ Miami Miller School of Medicine, Miami, Florida 33136
}

IL- $1 \beta$ and TNF are potential targets in the management of neuropathic pain after injury. However, the importance of the IL-1 and TNF systems for peripheral nerve regeneration and the mechanisms by which these cytokines mediate effects are to be fully elucidated. Here, we demonstrate that mRNA and protein levels of IL-1 $\beta$ and TNF are rapidly upregulated in the injured mouse sciatic nerve. Mice lacking both IL-1 $\beta$ and TNF, or both IL-1 type 1 receptor (IL-1R1) and TNF type 1 receptor (TNFR1), showed reduced nociceptive sensitivity (mechanical allodynia) compared with wild-type littermates after injury. Microinjecting recombinant IL-1 $\beta$ or TNF at the site of sciatic nerve injury in IL-1 $\beta$ - and TNF-knock-out mice restored mechanical pain thresholds back to levels observed in injured wild-type mice. Importantly, recovery of sciatic nerve function was impaired in IL-1 $\beta$-, TNF-, and IL-1 $\beta /$ TNF-knock-out mice. Notably, the infiltration of neutrophils was almost completely prevented in the sciatic nerve distal stump of mice lacking both IL-1R1 and TNFR1. Systemic treatment of mice with an anti-Ly6G antibody to deplete neutrophils, cells that play an essential role in the genesis of neuropathic pain, did not affect recovery of neurological function and peripheral axon regeneration. Together, these results suggest that targeting specific IL- $1 \beta /$ TNF-dependent responses, such as neutrophil infiltration, is a better therapeutic strategy for treatment of neuropathic pain after peripheral nerve injury than complete blockage of cytokine production.

\section{Introduction}

Cytokines such as IL- $1 \beta$ and TNF play a key role in the development and maintenance of pain after peripheral nerve injury or infection (Verri et al., 2006; Scholz and Woolf, 2007; Watkins et al., 2007). Although IL-1 $\beta$ and TNF may contribute to neuropathic pain by activating neurons directly, most studies suggest that these two cytokines modulate nociception indirectly, via the activation of non-neuronal nervous system cells (e.g., glial cells) and infiltration of immune cells. What remains largely unknown is the precise temporal expression pattern of these cytokines in the injured peripheral nervous system and the type of immune

Received June 7, 2011; accepted July 9, 2011.

Author contributions: S.L. designed research; S.N., M.F., J.Z., B.J.K., D.S., J.P.d.R.V., and S.L. performed research; S.R., Y.I., and S.L. contributed unpublished reagents/analytic tools; S.N., M.F., J.Z., J.P.d.R.V., R.W.K., and S.L. analyzed data; R.W.K. and S.L. wrote the paper.

*M.F. and J.Z. contributed equally to this work.

This study was supported by a grant from the Canadian Institutes of Health Research (CIHR) to S.L. (Grant MOP-84558). S.L. is supported by a Career Award from the Rx\&D Health Research Foundation and CIHR. We thank Nicolas Vallières, Nadia Fortin, and Xiang Qun Shi for their invaluable technical assistance.

Correspondence should be addressed to Dr. Steve Lacroix, Centre de recherche du Centre hospitalier de I'Université Laval, 2705 boulevard Laurier, Québec, QC G1V 4G2, Canada. E-mail: Steve.Lacroix@ crchul.ulaval.ca.

DOI:10.1523/JNEUROSCI.2840-11.2011

Copyright $\odot 2011$ the authors $\quad 0270-6474 / 11 / 3112533-10 \$ 15.00 / 0$ cells that are recruited to the injured site in an IL-1 $\beta /$ TNFdependent fashion.

Several reports indicate that immune cells contribute to pain after nerve injury (for review, see Watkins and Maier, 2002; Marchand et al., 2005; Austin and Moalem-Taylor, 2010), including one study that demonstrated that depletion of monocytes/macrophages through injection of clodronate-loaded liposomes resulted in a reduction in hyperalgesia (Liu et al., 2000). Since monocyte and macrophage heterogeneity may be complex (for review, see Gordon and Taylor, 2005), it is currently unknown whether a specific subset of monocytes/macrophages are responsible for these effects. In addition to monocytes and macrophages, both neutrophils and T lymphocytes have been shown to influence pain sensitivity after nerve trauma (Perkins and Tracey, 2000; Moalem et al., 2004). However, whether blocking the entry of specific immune cell subsets will provide an adequate treatment of pain after injury will have to be reevaluated by taking into consideration other key responses such as axonal regeneration, nerve repair, and functional recovery.

Since the inflammatory response that rapidly develops after peripheral nerve injury may contribute to both neuropathic pain and nerve regeneration, it is critical to determine the exact role(s) of immune cells and molecules in pathomechanisms after nerve 
Table 1. Summary of the primary antibodies used in the present study

\begin{tabular}{|c|c|c|c|c|c|}
\hline Antibody & Specificity & Immunogen/clone & Dilution & Source & Catalog/lot \# \\
\hline \multicolumn{6}{|l|}{ Flow cytometry } \\
\hline $\begin{array}{r}7 / 4 \text { (recently identified as } \\
\text { Ly-6B), PE-conjugated }\end{array}$ & $\begin{array}{l}\text { 25-30 kDa GPI-anchored protein expressed in } \\
\text { neutrophils and proinflammatory M1 } \\
\text { monocytes }\end{array}$ & Clone 7/4 & $1: 100$ & AbD Serotec & MCA771PE \\
\hline $\begin{array}{l}\text { CD11b (Integrin } \alpha \text { M chain, } \\
\text { Mac-1 } \alpha \text { chain), BD Hori- } \\
\text { zon V450-conjugated }\end{array}$ & $\begin{array}{l}\text { Murine } \alpha M \text { chain of Mac- } 1 \text { found on myeloid } \\
\text { cells }\end{array}$ & Clone M1/70 & $1: 333$ & BD Biosciences & $560455 / 65504$ \\
\hline $\begin{array}{l}\text { CD45 (Leukocyte Common } \\
\text { Antigen, Ly-5), PerCP- } \\
\text { conjugated }\end{array}$ & CD45 molecule on all leukocytes & Clone 30-F11 & $1: 167$ & BD Biosciences & $557235 / 51129$ \\
\hline Ly-6C, FITC-conjugated & $\begin{array}{l}\text { 14-17 kDa GPI-anchored protein expressed } \\
\text { at various levels in monocyte/macrophage } \\
\text { subsets, granulocytes, and T cell subsets }\end{array}$ & Clone AL-21 & $1: 500$ & BD Biosciences & $553104 / 41637$ \\
\hline Ly-6G, PE-Cy7-conjugated & $\begin{array}{l}21-25 \mathrm{kDa} \text { GPI-anchored protein expressed in } \\
\text { neutrophils }\end{array}$ & $\begin{array}{l}\text { Ly-6G-transfected EL4J cell line } \\
\text { Clone 1A8 }\end{array}$ & $1: 500$ & BD Biosciences & $560601 / 44917$ \\
\hline \multicolumn{6}{|l|}{ Immunofluorescence labeling } \\
\hline $7 / 4$ & $\begin{array}{l}25-30 \mathrm{kDa} \text { GPI-anchored protein expressed in } \\
\text { neutrophils and proinflammatory M1 } \\
\text { monocytes }\end{array}$ & Clone 7/4 & $1: 800$ & AbD Serotec & MCA771GA \\
\hline $\begin{array}{l}\text { Ionized calcium-binding } \\
\text { adaptor molecule } 1 \text { (iba1) }\end{array}$ & $\begin{array}{l}17 \mathrm{kDa} \text { EF hand protein expressed in } \\
\text { macrophages and microglia }\end{array}$ & $\begin{array}{l}\text { Synthetic peptide of C-terminus } \\
\text { iba1 N'-PTGPPAKKAISELP-C' }\end{array}$ & $1: 750$ & Wako & 019-19741/CDF1873 \\
\hline Ly-6G & $\begin{array}{l}21-25 \mathrm{kDa} \text { GPI-anchored protein expressed in } \\
\text { neutrophils }\end{array}$ & $\begin{array}{l}\text { Ly-6G-transfected EL4J cell line } \\
\text { Clone 1A8 }\end{array}$ & $1: 5000$ & BD Biosciences & $551459 / 26029$ \\
\hline \multicolumn{6}{|l|}{ Immunoblotting } \\
\hline$\beta$-Actin & $\begin{array}{l}\text { Antibody reacts with all vertebrate actin } \\
\text { isoforms }\end{array}$ & $\begin{array}{l}\text { Purified chicken gizzard actin } \\
\text { Clone C4 }\end{array}$ & $1: 7000$ & Millipore (Chemicon) & MAB1501 \\
\hline Caspase-1 & $\begin{array}{l}\text { Antibody reacts with full-length caspase- } 1 \\
\text { and cleaved forms that retain aa } 371-390\end{array}$ & $\begin{array}{l}\text { Synthetic peptide of amino } \\
\text { acids } 371-390 \text { of caspase-1 } \\
\text { (human) Clone 14F468 }\end{array}$ & $1: 300$ & Imgenex & IMG-5028/AB093004A-3 \\
\hline Interleukin-1 $\alpha(\mathrm{IL}-1 \alpha)$ & $\begin{array}{l}\text { Based on amino acid composition, the } \\
\text { theoretical MW of the recognized protein is } \\
31 \mathrm{kDa}\end{array}$ & $\begin{array}{l}\text { Highly pure }(>98 \%) \\
\text { recombinant mouse IL-1 } \alpha\end{array}$ & $1: 1250$ & Abcam & ab9724 \\
\hline Interleukin-1 $\beta$ (IL-1 $\beta)$ & $17 \mathrm{kDa}$ processed form of IL-1 $\beta$ & $\begin{array}{l}\text { Synthetic peptide of } \mathrm{N} \text {-terminal } \\
\text { region of mature IL-1 } \beta \\
\text { (human) }\end{array}$ & $1: 1000$ & Cell Signaling & 2021 \\
\hline Tumor necrosis factor $\alpha$ (TNF) & $\begin{array}{l}26 \mathrm{kDa} \text { membrane-bound TNF precursor } \\
\text { (pro-TNF) }\end{array}$ & $\begin{array}{l}\text { Recombinant full-length TNF } \\
\text { protein (human) }\end{array}$ & $1: 1250$ & Abcam & $a b 6671$ \\
\hline $\begin{array}{l}\text { TNF- } \alpha \text { converting enzyme } \\
\text { (TACE) }\end{array}$ & $\begin{array}{l}\text { Antibody reacts with mature, precursor and } \\
\text { glycosylated forms of TACE (also termed } \\
\text { Adam17) }\end{array}$ & $\begin{array}{l}\text { Synthetic peptide of C-terminus } \\
\text { TACE (human) }\end{array}$ & $1: 300$ & Lab Vision (NeoMarkers) & RB-1660-P/1660P807A \\
\hline
\end{tabular}

injury. A better knowledge of the functions of these cells and molecules could lead to the identification of new potential targets for treating neuropathic pain without interfering with the tissue repair program. In this study, we present the spatial and temporal distribution of mRNA and protein expression patterns of IL- $1 \alpha$, IL- $1 \beta$, and TNF in the injured peripheral nerve, using the sciatic nerve as a model. We analyzed roles of these cytokines in neuropathic pain and peripheral nerve regeneration. We demonstrate that IL- 1 and TNF pathways are involved in the recruitment of various immune cell subsets, such as neutrophils and proinflammatory M1 macrophages. Finally, we investigated whether depletion of neutrophils, which we have found to infiltrate the nerve distal stump in an IL-1/TNF-dependent fashion, affects repair processes such as axonal regeneration and functional recovery.

\section{Materials and Methods}

Animals. A total of 393 adult mice were used in this study. IL-1 $\beta$-ko mice in the C57BL/6 background were generated as previously described by the Iwakura laboratory (Horai et al., 1998). TNF- and IL-1 $\beta /$ TNF-ko mice and their wild-type (WT) counterparts were generated as described before by Turrin and Rivest (2006). IL-1R1/TNFR1-ko mice maintained on a mixed C57BL/ $6 \times 129$ background and their appropriate controls,
B6129SF2 mice, were purchased from The Jackson Laboratory. Thy1YFP-H transgenic mice (referred to as YFP mice throughout the text) were purchased from The Jackson Laboratory. For the experiments that dealt with neutrophil depletion, C57BL/6 mice from The Jackson Laboratory were used. All mice had ad libitum access to food and water.

Sciatic nerve injury and microinjection. The partial sciatic nerve ligation (PSNL) model was used to study neuropathic pain, following the method described in rats by Seltzer et al. (1990), and adapted to mice by Malmberg and Basbaum (1998). For all other experiments, a microcrush lesion of the left sciatic nerve was used as a model, following our previously published method (Boivin et al., 2007). As before, the lesion was made at midthigh level and the site of lesion was marked with a 10-0 Ethilon suture (Ethicon) passed through the epineurium only. Microinjections of carrier-free recombinant mouse $(\mathrm{rm})$ cytokines were made at the site of PSNL through a pulled-glass micropipette (30 $\mu \mathrm{m}$ external diameter) connected to a $2 \mu$ l Hamilton syringe. Immediately following PSNL injury, IL-1 $\beta$-, and TNF-ko mice were microinjected with rmIL-1 $\beta$ and rmTNF (amino acids 80-235), respectively, at a concentration of $10 \mathrm{ng} / \mu \mathrm{l}$ (R\&D Systems) in a final volume of $1 \mu \mathrm{l}$. All surgical procedures were approved by the Laval University Animal Care Committee (ACC) or McGill University ACC and followed Canadian Council on Animal Care guidelines.

Tissue processing. For experiments involving in situ hybridization (ISH), mice were overdosed with a mixture of ketamine and xylazine and 

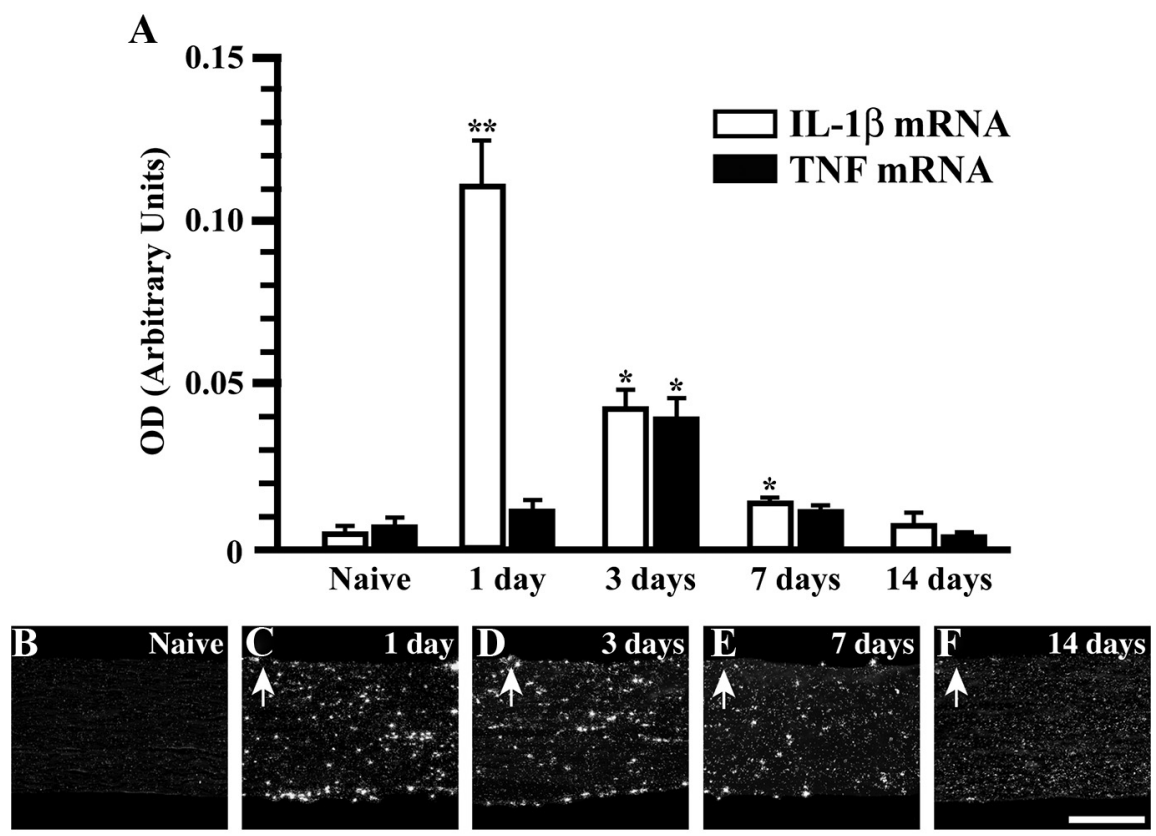

G

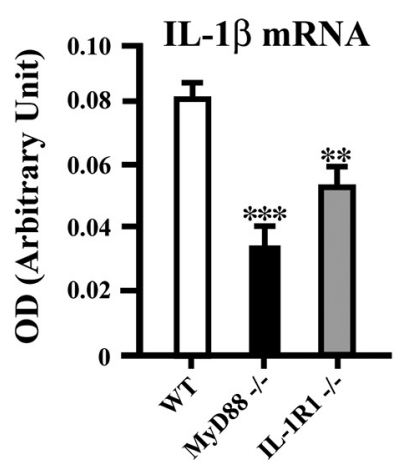

H

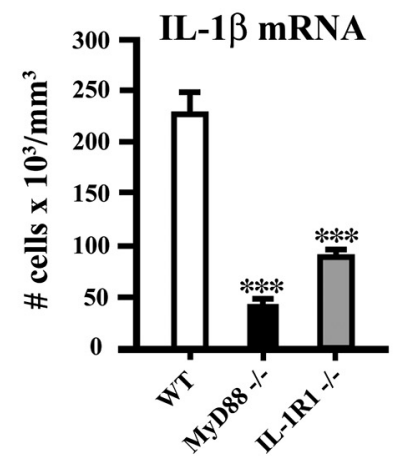

I
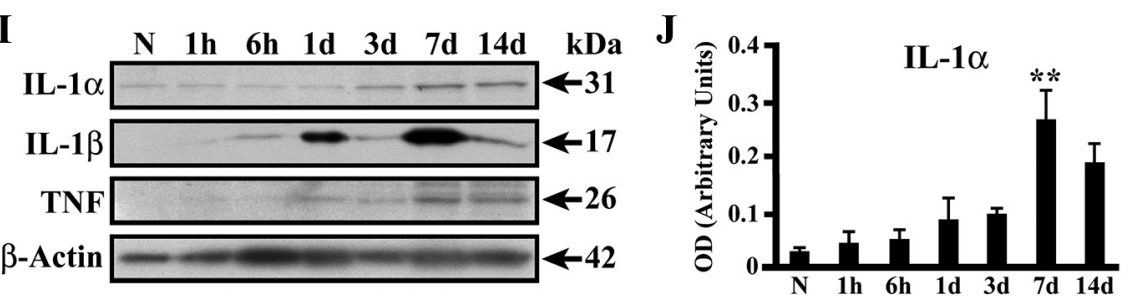

K
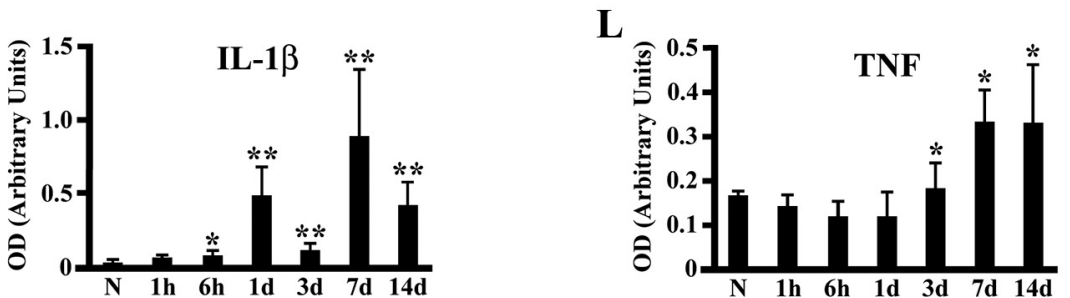

Figure 1. Sciatic nerve microcrush lesion rapidly induces production of the bioactive forms of IL-1 $\beta$ and TNF. $\boldsymbol{A}$, Quantification of in situ hybridization signal for IL-1 $\beta$ and TNF mRNA in the sciatic nerve distal stump at various times after lesion $(n=4$ mice/time point). $\boldsymbol{B}-\boldsymbol{F}$, Representative dark-field photomicrographs showing IL-1 $\beta$ mRNA expression at 0 ( $\boldsymbol{B}$; naive mouse), 1 (C), $3(\boldsymbol{D}), 7(\boldsymbol{E})$, and $14(\boldsymbol{F}) \mathrm{d}$ after sciatic nerve lesion in (57BL/6 mice. All photomicrographs were taken at $1 \mathrm{~mm}$ distal to the lesion. The arrows in $\boldsymbol{C} \boldsymbol{F}$ point to the $10-0$ suture node indicating the site of lesion. $\boldsymbol{G}-\boldsymbol{H}$, Quantification of ISH signal for IL-1 $\beta$ mRNA (G) and the number of cells expressing IL-1 $\beta$ mRNA $(\boldsymbol{H})$ in the sciatic nerve distal stump of MyD88- and IL-1R1-knock-out (-/-) mice and their WT littermates at $1 \mathrm{~d}$ after lesion ( $n=4$ per group). $I$, Representative immunoblots for IL- $1 \alpha$, IL-1 $\beta$ and TNF performed on cell lysate extracts obtained from the sciatic nerve of naive $(\mathrm{N})$ and injured $\mathrm{C} 57 \mathrm{BL} / 6$ mice at various times after lesion ( $n=4$ mice/time point). $J-L$, Immunoblot analysis of IL-1 $\alpha(31 \mathrm{kDa}), \mathrm{IL}-1 \beta(17 \mathrm{kDa})$, and TNF (26 kDa) proteins after sciatic nerve injury. The $\beta$-actin protein was used as internal standard and control for protein loading. ${ }^{* *} p<0.001,{ }^{* *} p<0.01$, and ${ }^{*} p<$ 0.05 compared with naive $(\boldsymbol{A}, \boldsymbol{J}-\boldsymbol{L})$ or WT $(\boldsymbol{G}-\boldsymbol{H})$ mice. Scale bar (in $\boldsymbol{F}) \boldsymbol{B}-\boldsymbol{F}, 250 \mu \mathrm{m}$. transcardially perfused with a $0.9 \%$ saline solution followed by $4 \%$ paraformaldehyde (PFA), in borax buffer, $\mathrm{pH}$ 9.5. After perfusion with the fixative, sciatic nerves were dissected out, postfixed for $2 \mathrm{~d}$, and placed overnight in a $4 \%$ PFA-borax/10\% sucrose solution until tissue processing. For the purpose of histological and immunohistochemical labeling, animals were perfused instead with cold PBS followed by $4 \%$ PFA, pH 7.4, in PBS. Sciatic nerves were postfixed for $1 \mathrm{~h}$ only and then placed in a PBS/20\% sucrose solution until sectioning. Sciatic nerves were cut longitudinally using a cryostat (model CM3050S; Leica Microsystems) set at a thickness of $14 \mu \mathrm{m}$. Sciatic nerve sections were collected directly onto slides having a permanent positively charged surface (Surgipath Canada), separated into five different series of adjacent sections, and then stored at $-20^{\circ} \mathrm{C}$.

ISH. ISH was performed to detect mRNAs coding for IL- $1 \beta$ and TNF, following our previously published method (Boivin et al., 2007).

Flow cytometry and immunofluorescence labeling. Immune cells that infiltrated the injured sciatic nerve were characterized using flow cytometry analysis and multiple immunofluorescence labeling, according to our previously published methods (Barrette et al., 2008). The complete description of the primary antibodies used in this study is given in Table 1.

Quantification of ISH signal, flow cytometry, and immunofluorescence labeling. The average density of ISH signal was measured within predefined $1 \mathrm{~mm}$ sciatic nerve segments, starting from the site of injury up to $4 \mathrm{~mm}$ distal to the lesion, as described before (Boivin et al., 2007).

For flow cytometry analysis, cells isolated from a $8 \mathrm{~mm}$ sciatic nerve segment, extending from $1 \mathrm{~mm}$ rostral to the site of injury up to 7 $\mathrm{mm}$ distal, were analyzed using FlowJo software (v. 9.2; Tree Star) on a FACS LSRII flow cytometer (BD Biosciences). The LIVE/DEAD Fixable Yellow Dead Cell Stain Kit (Invitrogen Canada) was used to distinguish live from dead cells. Myeloid cells were identified based on their expression of CD45, CD11b, 7/4, Ly-6C, and Ly6G, as follow: neutrophils, $\mathrm{CD} 5^{+} \mathrm{CD} 11 \mathrm{~b}^{+}$ $7 / 4^{+}$Ly-6C ${ }^{+}$Ly-6G ${ }^{+}$; M1 macrophages, $\mathrm{CD}_{4}{ }^{+} \mathrm{CD}_{11 b^{+}}{ }^{+} / 4^{+} \mathrm{Ly}^{-6 C^{\text {hi }}} \mathrm{Ly}-6 \mathrm{G}^{-}$; M2 macrophages, $\mathrm{CD} 45^{+} \mathrm{CD} 11 \mathrm{~b}{ }^{+} 7 / 4^{-} \mathrm{Ly}^{+} 6 \mathrm{C}^{\text {lo }}$ Ly-6G ${ }^{-}$(Gordon and Taylor, 2005; Nahrendorf et al., 2007).

For immunohistological analysis, monocytes/macrophages were identified based on their expression of the ibal marker (Boivin et al., 2007; Audoy-Rémus et al., 2008). Expression of the 7/4 antigen and nuclear morphology (i.e., round, ovoid, or kidney-shaped nucleus that occupies up to $50 \%$ of the overall cell area) were further used to define the population of M1 macrophages, as described previously (Henderson et al., 2003; Gordon and Taylor, 2005; Tsou et al., 2007). Neutrophils were identified based on their expression of the $7 / 4$ and Ly-6G antigens, lack of expression of iba1, and a multilobed nucleus (Stirling and Yong, 2008). For the quantification of neutrophils and M1 macrophages, the outline of the 
longitudinal section was traced at $20 \times$ magnification and a grid of 50 $\mu \mathrm{m} \times 50 \mu \mathrm{m}$ positioned over the nerve using the Bioquant Nova Prime software (Bioquant Image Analysis Corporation). All cells with a visible nucleus were then counted at $100 \times$ magnification.

Three-dimensional reconstruction and modeling. Three-dimensional reconstructions of leukocytes were generated from confocal image stacks acquired using an Olympus Fluoview microscope (BX61) using the Imaris software (v. 4.5; Bitplane), following the method described previously (Audoy-Rémus et al., 2008).

Immunoblot analyses. Immunoblotting was performed on cell lysate extracts obtained from the sciatic nerve of naive and injured mice (each using $n=4$ mice per time point). Four-millimeter-long sciatic nerve segments, starting from the site of injury up to $4 \mathrm{~mm}$ distal to the lesion, were homogenized and subjected to immunoblotting analysis with primary antibodies listed in Table 1, following our previously published method (de Rivero Vaccari et al., 2008).

Behavioral analyses. Mechanical allodynia was measured using calibrated von Frey filaments (Stoelting; see Fig. $3 A, C$ ), following our previously published method (Zhang et al., 2007). Animals were habituated to the testing environment daily for at least $2 \mathrm{~d}$ before baseline testing. Before experimentation, mice were allowed to acclimatize for at least $1 \mathrm{~h}$ in individual plastic boxes with a wire mesh floor. A set of eight calibrated von Frey filaments (ranging from 0.008 to $1.4 \times g$ ) were applied to the plantar surface of the hindpaw until they bent. The threshold force required to elicit withdrawal of the paw (median $50 \%$ paw withdrawal) was determined as the average of two tests separated by at least $1 \mathrm{~h}$. As well, the Ugo Basile Dynamic Plantar Anesthesiometer apparatus (Stoelting) was used to measure allodynia in IL- $1 \beta$-, TNF-, IL- $1 \beta /$ TNF-ko mice (see Fig. 3B).

Recovery of locomotor function after sciatic nerve lesion was quantified using the sciatic nerve functional index (SFI), as described before (Boivin et al., 2007). This test was performed for all animals preoperatively and every week after the operation up to 7 weeks. The SFI was measured using the formula adapted for mice by Inserra et al. (1998).

Depletion of neutrophils and sciatic-sciatic nerve grafts. Neutrophils were depleted through repeated intravenous injections with monoclonal anti-mouse Ly-6G antibody, clone 1A8, purchased from BioXCell. Rat IgG2a isotype (clone 2A3; BioXCell) and PBS served as controls. Mice were injected with $100 \mu \mathrm{l}$ of antibody at $0.1 \mu \mathrm{g} / \mu \mathrm{l}$ or PBS at $12 \mathrm{~h}$ before the lesion, at the time of the lesion, at 12 and $24 \mathrm{~h}$ after lesion, and then every day until day 4.

To investigate the capacity of peripheral axons to regenerate in the absence of neutrophils, we performed experiments in which predegenerated sciatic nerve segments collected from $\mathrm{YFP}^{-}$mice treated with an anti-Ly-6G antibody, isotype control antibody, or PBS were grafted to the sciatic nerve of $\mathrm{YFP}^{+}$recipient mice, allowing to visualize $\mathrm{YFP}^{+}$axons that had regenerated into grafts [for a complete description of the surgical procedure followed to perform the allografts, please refer to Barrette et al. (2008)]. We note that recipient mice were also treated with anti-Ly-6G antibody, isotype control antibody, or PBS. Mice were killed at $7 \mathrm{~d}$ after grafting and quantification performed as described before (Barrette et al., 2008).

Statistical analysis. All statistical evaluations were performed with one- or two-way ANOVA or repeated-measures ANOVA. Post-ANOVA comparisons were made using the Bonferroni correction. All statistical analyses were performed using the GraphPad Prism software (GraphPad Software). Data in graphs are presented as mean \pm SEM.

\section{Results}

The biologically active forms of IL-1 $\beta$ and TNF are rapidly produced in the peripheral nerve distal stump after injury Using ISH and immunoblotting, we first examined the relative expression levels for IL- $1 \beta$ and TNF mRNA and protein in the sciatic nerve of naive and injured C57BL/6 mice.

\section{$I L-1 \beta$}

As shown in Figure $1, A$ and $B$, no ISH signal for IL- $1 \beta$ was detected in sciatic nerve sections obtained from naive mice. How-
A
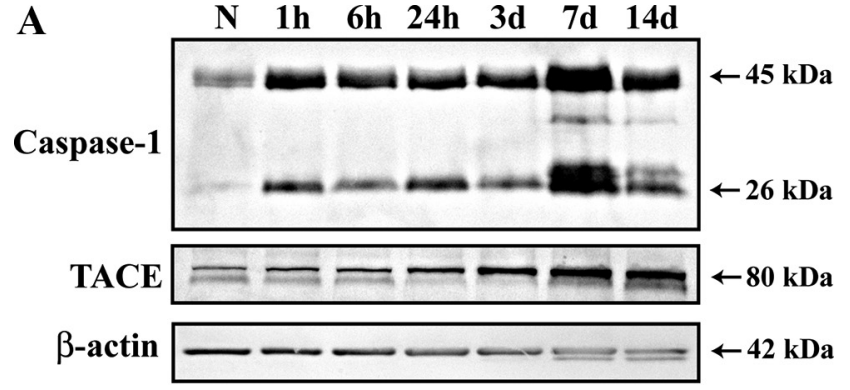

B

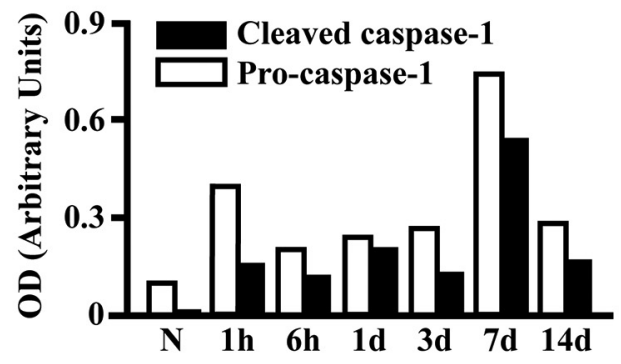

C

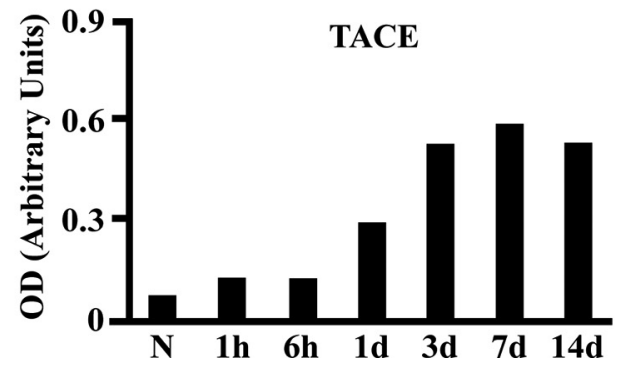

Figure 2. The active forms of the enzymes that mediate the proteolytic cleavage of the pro-forms of IL- $1 \beta$ and TNF into mature (secreted) cytokines are upregulated in the sciatic nerve distal stump after microcrush lesion. $\boldsymbol{A}$, Representative immunoblots for caspase- 1 and TACE performed on cell lysate extracts obtained from the sciatic nerve of naive and injured C57BL/6 mice at various times after lesion. $\boldsymbol{B}, \boldsymbol{C}$, Quantification of immunoblot analysis of caspase-1 $(\boldsymbol{B})$ and TACE ( $\boldsymbol{C}$ protein expression revealed that the precursor forms for caspase-1 $(45 \mathrm{kDa})$ and TACE $(\sim 100 \mathrm{kDa}$ ) were rapidly converted into the active forms of 26 and $\sim 80 \mathrm{kDa}$, respectively, after injury. The $\beta$-actin protein was used as internal standard and control for protein loading.

ever, signal expression changed drastically after a sciatic nerve lesion. At $1 \mathrm{~h}$ after lesion, cells expressing IL-1 $\beta$ could be readily detected, although in limited numbers (see Boivin et al., 2007). IL- $1 \beta$ mRNA levels peaked at day 1 and then decreased progressively thereafter (Fig. $1 A$ ), to eventually return to baseline levels by day 14 after lesion. For all time points studied, quantitative analyses revealed that IL- $1 \beta$ mRNA expression was preferentially increased in areas located near the lesion site (Fig. $1 C-E$ ). Notably, we found that IL-1 $\beta$ mRNA expression was abolished in the sciatic nerve distal stump of MyD88- and IL-1R1-knock-out (ko) mice (Fig. $1 G, H$ ). We also found that sciatic nerve cells contain constitutive levels of the precursor form $(31 \mathrm{kDa})$ of IL- $1 \alpha$ (Fig. $1 I, J)$, which is known to be biologically active (Dinarello, 2009).

To determine whether sciatic nerve lesion induced the cleavage of the IL- $1 \beta$ precursor into its biologically active $17 \mathrm{kDa}$ form, we performed immunoblot analysis on sciatic nerve lysates. Protein levels for the mature form of IL- $1 \beta$ increased almost immediately after injury, with increases of $\sim 2$-fold and 10 -fold after $6 \mathrm{~h}$ and $1 \mathrm{~d}$, respectively, compared to levels detected in naive animals (Fig. $1 I, K$ ). Immunoblots showed that IL- $1 \beta$ protein re- 

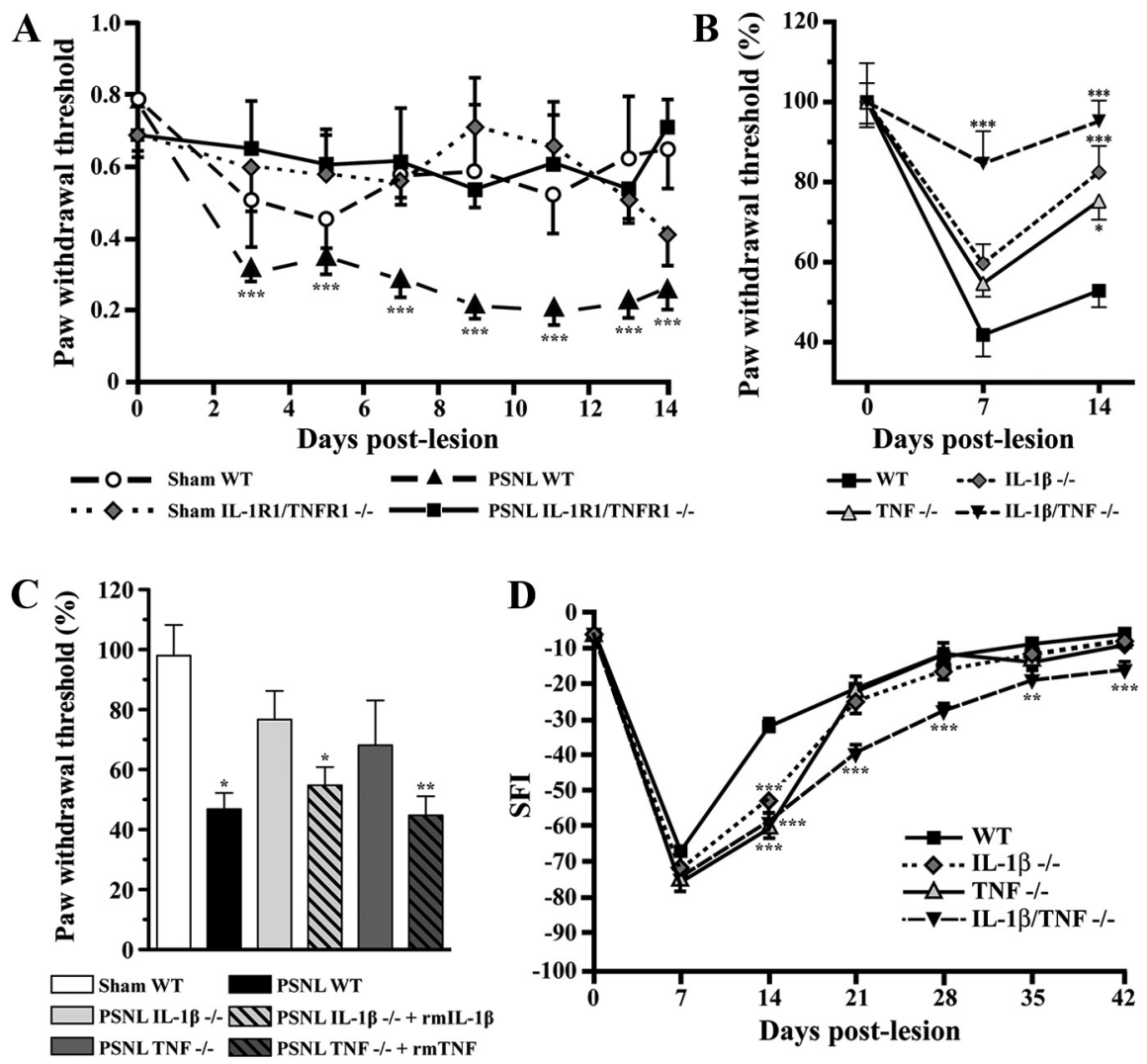

Figure 3. IL-1 $\beta$ and TNF are major factors contributing to pain after peripheral nerve injury and are critical for recovery of neurological function. $A$, Paw withdrawal threshold (in grams) to mechanical stimulation following PSNL or sham-operation ( $n=$ 4-6 mice/group). WT mice showed a robust decrease in withdrawal threshold on the hindpaw ipsilateral to nerve injury at day 3 and maintained this hypersensitivity until the end of the testing period. In contrast, mechanical allodynia was almost completely abolished in IL-1R1/TNFR1 double knock-out (-/ - ) mice. B, Paw withdrawal thresholds (expressed as percentage of baseline) of IL- $1 \beta-/-$, TNF $-/-$, and IL-1 $\beta /$ TNF $-/-$ mice compared with WT mice after sciatic nerve injury ( $n=11$ mice/group). C, Paw withdrawal thresholds (percentage of baseline) of IL- $1 \beta-/-$ and TNF $-/$ - mice following PSNL and injection of recombinant mouse IL-1 $\beta$ (rmlL-1 $\beta$ ) or TNF (rmTNF) into the sciatic nerve at $7 \mathrm{~d}(n=6-9$ mice/group). $\boldsymbol{D}$, Recovery of sciatic nerve function after microcrush lesion, as determined by the SFI, in IL- $1 \beta-1-$, TNF $-/-$, and IL- $1 \beta /$ TNF $-1-$ mice compared with WT mice over a period of $42 \mathrm{~d}$ ( $n=10-32$ mice/group). ${ }^{* * *} p<0.001,{ }^{* *} p<0.01$, and ${ }^{*} p<0.05$ compared with baseline levels in the same group $(\boldsymbol{A})$, WT $(\boldsymbol{B}, \boldsymbol{D})$, or sham WT $(\boldsymbol{C})$.

mains at high levels for several days after injury, with two peaks of expression observed at day 1 and day 7.

We next evaluated whether caspase-1, a component of inflammasomes that are involved in the proteolytic activation of IL- $1 \beta$ (de Rivero Vaccari et al., 2008), was altered following nerve injury (Fig. $2 A, B)$. Both pro-caspase- $1(45 \mathrm{kDa})$ and active (cleaved) caspase-1 $(26 \mathrm{kDa})$ protein levels were modulated in sciatic nerve lysates. The time course of pro-caspase-1 processing was similar to that of IL-1 $\beta$ maturation. Together, these data demonstrate that sciatic nerve lesion results in the acute activation of IL- $1 \beta$ transcription, synthesis of pro-IL- $1 \beta$, activation of caspase- 1 , and cleavage of inactive pro-IL- $1 \beta$ into its biologically active form.

\section{TNF}

Cells expressing TNF mRNA were also detected early following peripheral nerve injury $(<1 \mathrm{~h})$, although only few scattered positive cells were seen during the first $24 \mathrm{~h}$ following lesion. A small but significant upregulation of TNF mRNA in the sciatic nerve distal stump was detected at one time point only, i.e., at $3 \mathrm{~d}$ after injury (Fig. 1A). As shown in Figure $1 \mathrm{I}$, the transmembrane precursor form of TNF $(26 \mathrm{kDa})$ was detected by immunoblotting in sciatic nerve lysates from injured animals at 3, 7, and $14 \mathrm{~d}$. Although the levels of the mature $17 \mathrm{kDa}$ soluble form of TNF were below the detection limit of our assay, an increase in the expression of the active form of the TNF- $\alpha$ converting enzyme (TACE; corresponding to the $80 \mathrm{kDa}$ band) was clearly detected from day 1 to day 14 after injury (Fig. 2A,C). That the $17 \mathrm{kDa}$ form of TNF is released in the latter interval would be consistent with results from a previous study performed in rats using a chronic constriction injury model (Shubayev and Myers, 2000). Thus, in addition to IL- $1 \beta$, TNF is another ideal marker for the rapid initiation of the inflammatory response upon nerve injury.

Mechanical allodynia induced by sciatic nerve injury is compromised in mice lacking both IL-1 $\beta$ and TNF or their type 1 receptors (IL-1R1 and TNFR1)

To confirm earlier reports that neuropathic pain arising after peripheral nerve injury is modulated, at least in part, by IL- $1 \beta$ and TNF (for review, see Verri et al., 2006; Scholz and Woolf, 2007; Watkins et al., 2007), we examined signs of mechanical allodynia in IL-1R1/TNFR1-ko mice. As shown in Figure $3 A$, preoperative values for mechanical pain hypersensitivity of IL-1R1/TNFR1-ko mice and their WT littermates were almost identical. A significant decrease in the paw withdrawal threshold was observed when a mechanical touch stimulus was applied on the plantar surface of the nerve-injured paw. However, IL-1R1/TNFR1-ko mice were significantly less sensitive to mechanical pain after injury than control mice at all time points investigated. The differences in scores of noninjured WT, noninjured IL-1R1/TNFR1-ko, and injured IL-1R1/ TNFR1-ko mice did not reach statistical significance at any time in this study, indicating that IL-1R1/ TNFR1-ko animals are refractory to mechanical allodynia in the partial sciatic nerve ligation model. Further analysis using IL- $1 \beta$-, TNF-, and IL-1 $\beta /$ TNF-ko mice revealed that both cytokines needed to be absent for complete elimination of pain (Fig. 3B). Microinjection of recombinant mouse IL- $1 \beta$ and TNF at the site of sciatic nerve injury in IL-1 $\beta$ - and TNF-ko mice, respectively, restored mechanical pain thresholds back to levels observed in injured WT mice (Fig. $3 C$ ). This suggests that IL- $1 \beta$ and TNF contribute to neuropathic pain by acting locally at sites of peripheral nerve injury. Together, these results indicate the importance of the IL-1 and TNF signaling pathways in the development of neuropathic pain (allodynia) after peripheral nerve injury.

Functional recovery after sciatic nerve lesion is impaired in the absence of IL- $1 \boldsymbol{\beta}$ and TNF

Based on our previous finding that inflammation is required for axonal regeneration (Boivin et al., 2007; Barrette et al., 2008), we next investigated whether functional recovery was affected in mice lacking IL- $1 \beta$ or TNF after sciatic nerve injury. Since depletion of either IL- $1 \beta$ or TNF may activate compensatory mechanisms that lead to overproduction of these inflammatory 

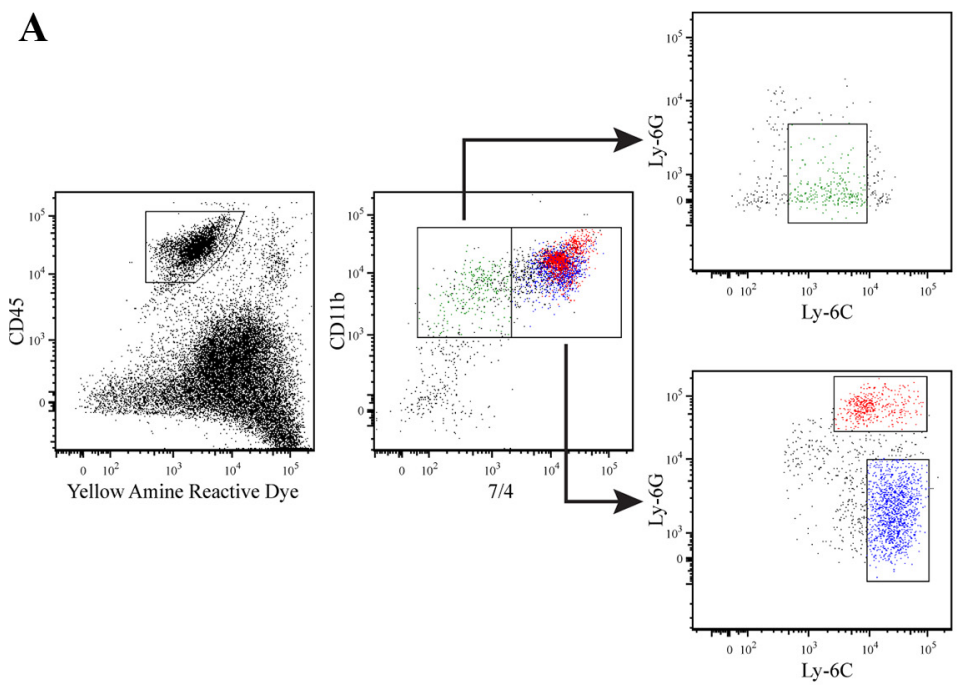

B
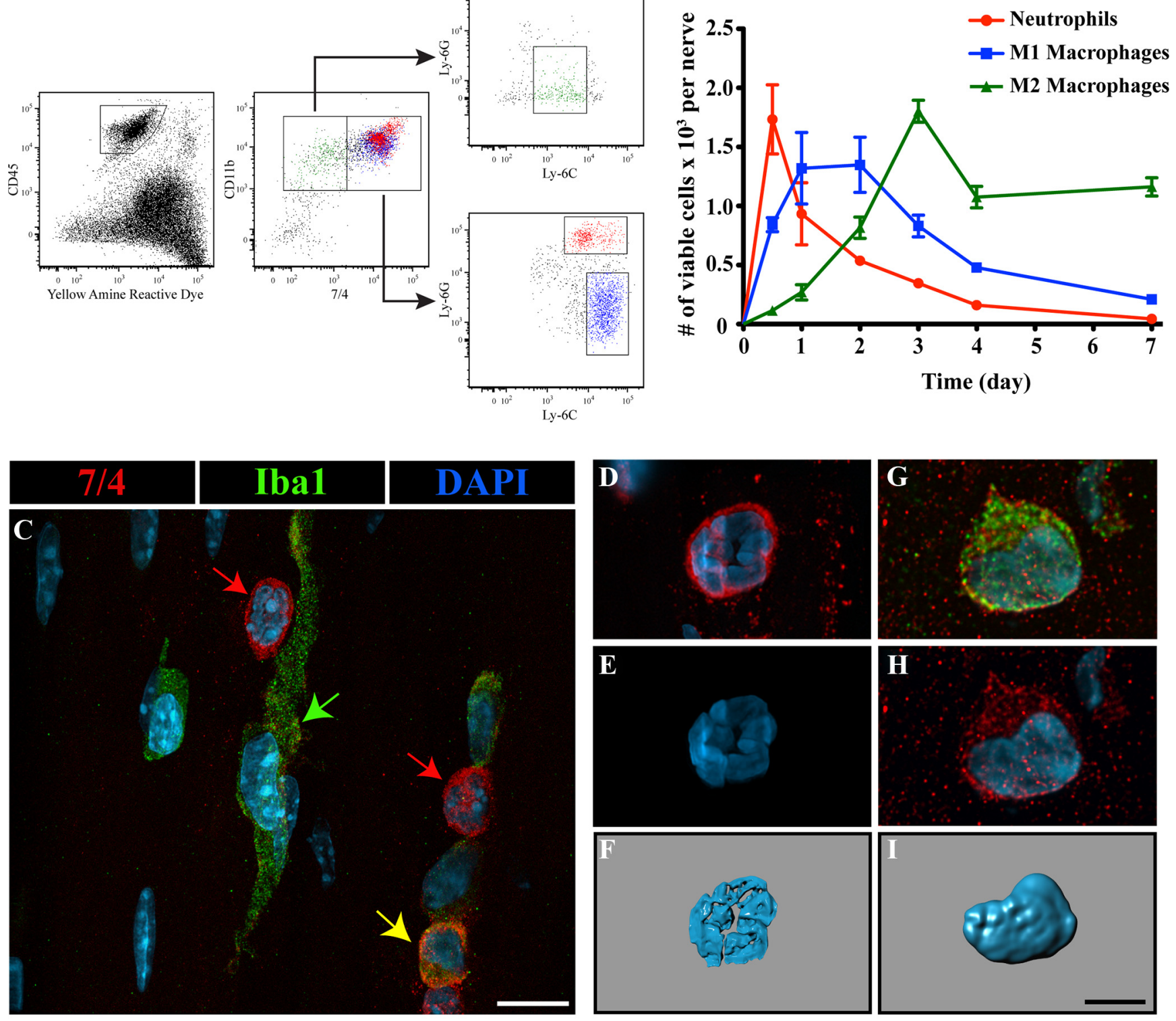

\section{J}
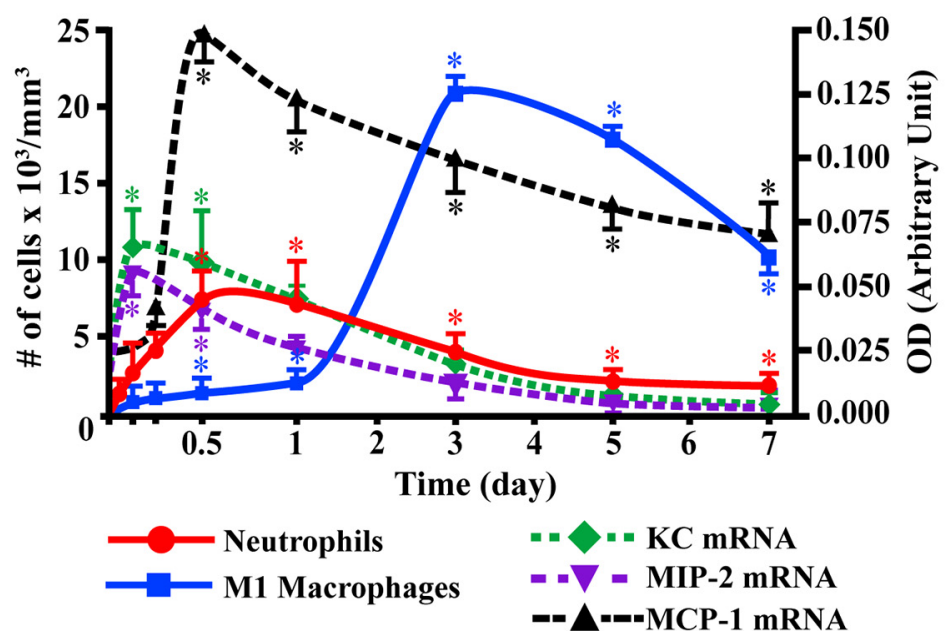

Figure 4. Time course of neutrophil and macrophage influx in the mouse sciatic nerve after microcrush lesion. $A$, Representative flow cytometry profiles showing the presence of neutrophils (red;

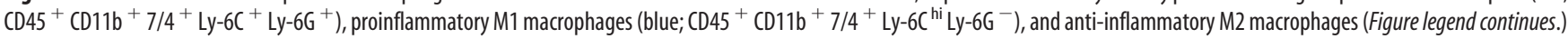


cytokines, mice deficient in both IL-1 $\beta$ and TNF genes were included in our analyses.

Recovery of neurological function was assessed by measuring the SFI (Fig. 3D). No significant differences were observed in the preoperative SFI values among the four different groups included in this experiment. When compared with control mice, statistical significance for SFI values of IL-1 $\beta$ /TNF-ko mice was measured at $7,14,21,28,35$, and $42 \mathrm{~d}$ after injury. IL- $1 \beta$ - and TNF-ko mice exhibited significant locomotor deficits compared with WT at both 7 and $14 \mathrm{~d}$. Thus, it appears that IL- $1 \beta$ and TNF are important for recovery of sciatic nerve function after injury, and that neutralization of the actions of these proinflammatory cytokines most likely impairs peripheral nerve regeneration.

Neutrophil infiltration is prevented in the sciatic nerve distal stump of mice lacking both IL-1R1 and TNFR1

Neutrophils and monocytes are two cell types that rapidly infiltrate the injured nervous system. However, recent studies have revealed considerable heterogeneity in monocyte/macrophage populations and identified at least two different subsets of monocyte-derived macrophages: "classically activated" proinflammatory (M1) macrophages and "alternatively activated" anti-inflammatory (M2) macrophages (for review, see Gordon and Taylor, 2005). Using flow cytometry and multiple immunofluorescence labeling, we first performed a time course to establish the timing and magnitude of neutrophil, M1 macrophage, and M2 macrophage presence in the injured sciatic nerve (Fig. 4). By $3 \mathrm{~h}$, both neutrophils and monocytes infiltrated the injured sciatic nerve. However, quantitative analyses revealed that neutrophils were present in greater numbers acutely after injury, with a peak of infiltration observed at 12-24 h after injury. Proinflammatory M1 monocytes/macrophages also infiltrated rapidly following peripheral nerve injury and similar numbers were present by 1-2 d. Maximal infiltration for monocyte-derived M1 macrophages was observed at 2-3 d, followed by a progressive decrease by day 7 . Notably, recruitment of neutrophils and monocytes that differentiate into M1 macrophages paralleled the endoneurial expression of their respective murine chemoattractant chemokines, i.e., KC/CXCL1 and MIP-2/CXCL2 for neutrophils and MCP-1/CCL2 for M1 monocytes/macrophages (Fig. $4 J$ ).

We next determined the number of neutrophils and M1 macrophages present at various locations distal to the lesion site in the sciatic nerve of IL-1R1/TNFR1-ko mice and their WT littermates. At $1 \mathrm{~d}$ after injury, the number of multilobed $7 / 4^{+}$ibal ${ }^{-}$neutrophils was reduced by $~ 95 \%$ in IL-1R1/TNFR1-ko mice com-

$\leftarrow$

(Figure legend continued.) (green; $\mathrm{CD} 45^{+} \mathrm{CD}_{11 \mathrm{~b}^{+}} 7 / 4^{-} \mathrm{Ly}-6 \mathrm{C}^{\mathrm{lo}} \mathrm{Ly}-6 \mathrm{G}^{-}$) in the sciatic nerve distal stump of C57BL/6 mice at $24 \mathrm{~h}$ after injury. $\boldsymbol{B}$, Time course of the presence of neutrophils, M1 macrophages, and M2 macrophages in the sciatic nerve distal stump of C57BL/6 mice during the first week after lesion ( $n=4$ mice per time point), as revealed by flow cytometry. $C-I$, Confocal images and $3 \mathrm{D}$ reconstructions of $Z$-stacks showing $7 / 4^{+}$neutrophils with their characteristic multilobed, segmented nuclei (cells pointed to by red arrows in C and D-F) and proinflammatory M1 macrophages $\left(7 / 4^{+}\right.$iba $1^{+}$cells with monolobed or bilobed nuclei; cell pointed to by the yellow arrow in $($ and $\mathbf{G}-\boldsymbol{I}$ ) in the sciatic nerve distal stump at day 1 after lesion. Note that some elongated iba ${ }^{+}$cells did not express the $7 / 4$ marker, suggesting that they could be resident endoneurial macrophages (see the cell pointed to by the green arrow in C). Nuclear counterstaining with DAPI is shown in blue. J, Time course of the presence of neutrophils, M1 macrophages, and M2 macrophages in the sciatic nerve distal stump of $\mathrm{C} 57 \mathrm{BL} / 6$ mice during the first week after lesion ( $n=4$ mice per time point), as revealed by multiple immunofluorescence labeling. Also shown in $J$ is the expression of the neutrophil chemoattractants KC/CXCL1 and MIP-2/CXCL2 and the monocyte chemoattractant protein-1 (MCP-1, also termed CCL2) at the mRNA level. ${ }^{*} p<0.05$ compared with naive mice (J). Scale bars: (in $C$ C, $10 \mu \mathrm{m}$; (in I) D-I, $6 \mu \mathrm{m}$.
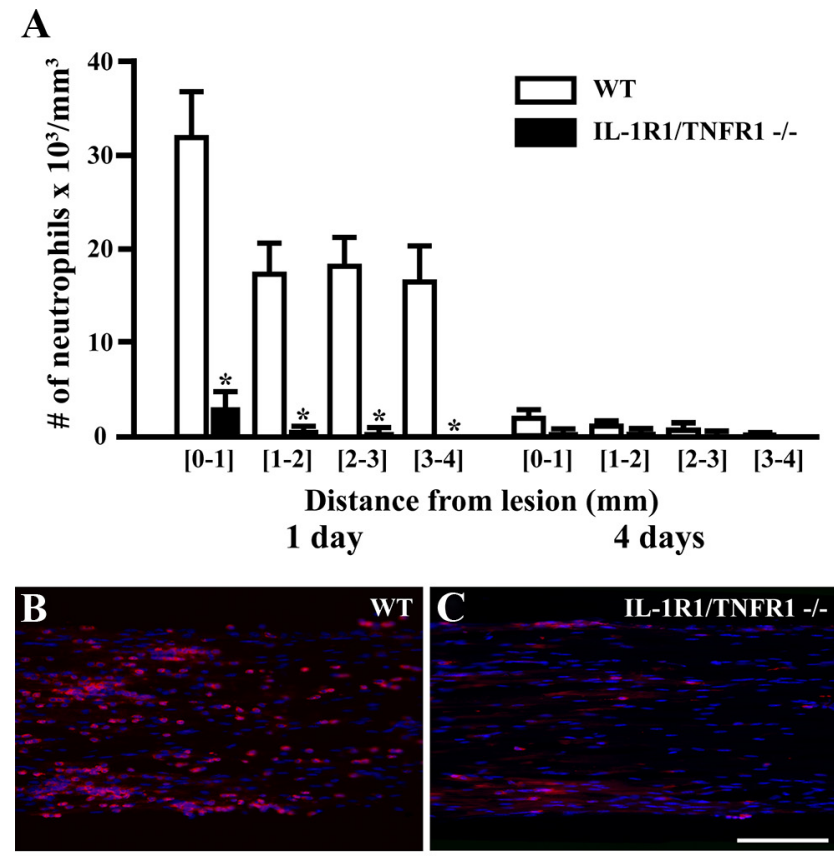

D

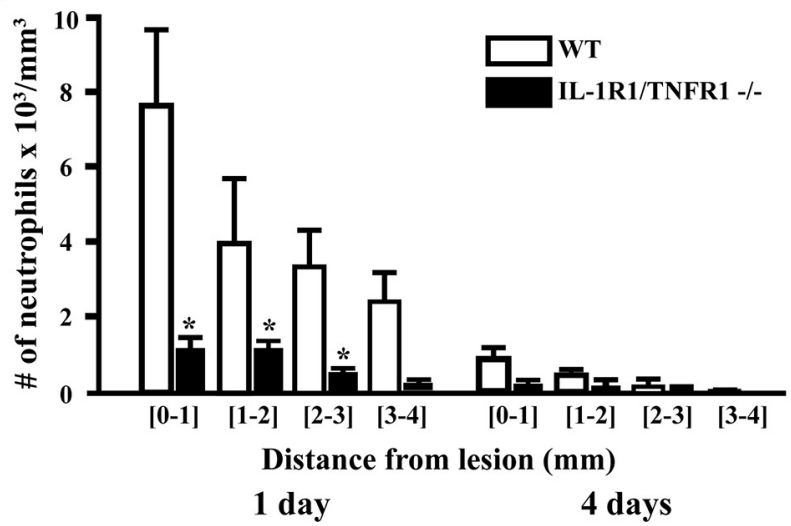

Figure 5. Neutrophils are recruited in an IL-1/TNF-dependent fashion after peripheral nerve injury. A, Quantification of the number of multilobed $7 / 4^{+}$iba $1^{-}$neutrophils in the sciatic nerve distal stump of IL-1R1/TNFR1 double-knock-out (-/-) mice and their WT littermates at 1 and $4 \mathrm{~d}$ after microcrush lesion ( $n=4$ mice per group per time point). $B, C$, Representative photomicrographs showing $7 / 4$ immunostaining in the sciatic nerve distal stump of WT $(\boldsymbol{B})$ and IL-1R1/TNFR1 - / - (C) mice at $1 \mathrm{~d}$ after injury. D, Quantification of the number of Ly-6G ${ }^{+}$ neutrophils in the sciatic nerve distal stump of IL-1R1/TNFR1 $-/-$ mice and their WT littermates at 1 and $4 \mathrm{~d}$ after lesion ( $n=4$ per group per time point). ${ }^{*} p<0.05$ compared with WT mice. Scale bar (in C) $B, C, 150 \mu \mathrm{m}$.

pared to WT (Fig. 5A-C). This reduction in neutrophil numbers was maintained at $4 \mathrm{~d}(\sim 60 \%$ reduction), yet neutrophils were observed in limited numbers at this time. Neutrophil numbers at both time points were confirmed by immunodetection of the neutrophil-specific antigen Ly-6G (Fig. 5D). The absence of both IL-1R1 and TNFR1 also led to a $90 \%$ and $8 \%$ reduction in the number of $7 / 4^{+} \mathrm{M} 1$ macrophages at 1 and $4 \mathrm{~d}$, respectively. Thus, the recruitment of neutrophils and proinflammatory M1 monocytes/macrophages depends on IL-1R1 and TNFR1 signaling.

Neutrophil depletion decreases pain without interfering with axonal regeneration and recovery of sciatic nerve function To establish whether neutrophils are essential for nerve repair, we depleted neutrophils by repeated injection of the sciatic nerveinjured mice with a monoclonal antibody directed against the 
Ly-6G antigen that is specifically expressed by neutrophils. Sciatic nerves were collected at 1 and $4 \mathrm{~d}$ after lesion and processed for immunostaining of Ly-6G, $7 / 4$, and ibal to determine the efficacy of neutrophil depletion, As demonstrated in Figure $6 A$, the number of Ly- $6 \mathrm{G}^{+}$neutrophils in the sciatic nerve distal stump of mice treated with the anti-Ly-6G antibody was reduced by $\sim 85 \%$ and $80 \%$ compared with PBS-treated and isotype controltreated animals, respectively, at day 1 . To rule out the possibility that the Ly-6G antibody remains on the surface of viable neutrophils for extended periods and masks Ly-6G antigenic sites to prevent binding of subsequently applied anti-Ly-6G antiserum, immunostaining was also performed using an antibody directed against the 7/4 antigen. DAPI counterstaining was used to discriminate neutrophils from M1 macrophages (Fig. 4C-I). Quantification of 7/4 ${ }^{+}$ cells exhibiting a multilobed, segmented nucleus confirmed that anti-Ly-6G treatment resulted in pronounced neutrophil depletion within the injured sciatic nerve (Fig. $6 B)$. Notably, the number of $7 / 4^{+} \mathrm{M} 1$ macrophages did not change as a result of the anti-Ly-6G treatment (Fig. 6C).

To first establish whether neutrophil depletion attenuates the development of neuropathic pain, mechanical allodynia was measured using von Frey filaments. Mice treated with PBS or isotype control antibody showed a decrease in withdrawal thresholds under conditions of partial sciatic nerve injury (Fig. 6D). In contrast, neutrophil-depleted mice failed to develop allodynia during the entire duration of anti-Ly-6G treatment (i.e., $4 \mathrm{~d}$ ). Next, we examined hindlimb motor improvement using the SFI to determine whether neutrophil depletion would interfere with recovery of sciatic nerve function after lesion. No significant differences were observed in the preoperative and postoperative SFI values among all groups of mice (Fig. $6 E$ ). This result suggests that neutrophil depletion decreases pain without interfering with the nerve regeneration process.

To further confirm that axonal regeneration was not affected by the deficit in neutrophils, we used a mouse model in which the YFP marker is expressed in a defined subset of their neurons and axons for the convenient visualization of axonal regeneration. We determined the total number of $\mathrm{YFP}^{+}$sciatic nerve axons that regenerated into $\mathrm{YFP}^{-}$peripheral nerve allografts at $7 \mathrm{~d}$ after surgery following treatment with PBS, isotype control antibody, or anti-Ly-6G antibody. Proximal to the graft at $7 \mathrm{~d}$ after surgery, no significant differences in the count of $\mathrm{YFP}^{+}$axons was found between the three different groups: $\mathrm{PBS}, 63 \pm 4.7$; isotype control antibody, $56 \pm 3.2$; anti-Ly-6G antibody, $63 \pm 6.4$. Similarly, the average number of $\mathrm{YFP}^{+}$axons at specific distances into the pre-degenerated sciatic nerve grafts did not change between groups (Fig. 6F). Together with our results that show that recovery of sciatic nerve function is not altered in injured mice treated with the anti-Ly-6G, these data indicate that neutrophils are not essential for peripheral nerve regeneration.

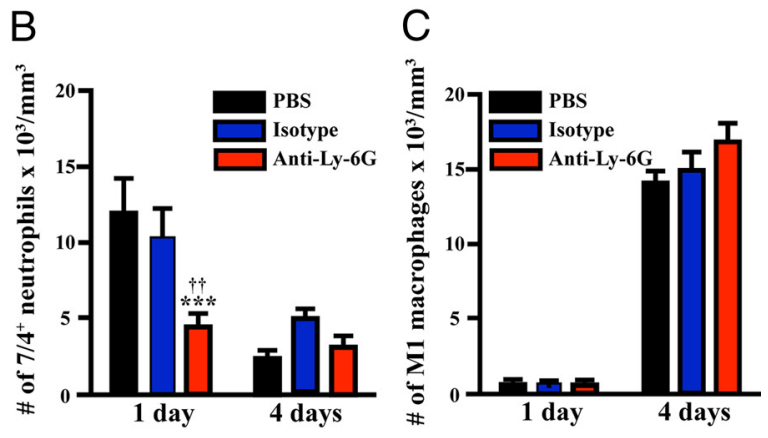

E

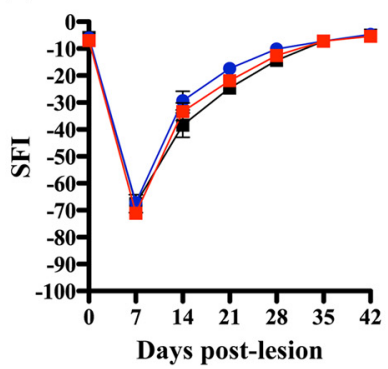

$\mathrm{F}$

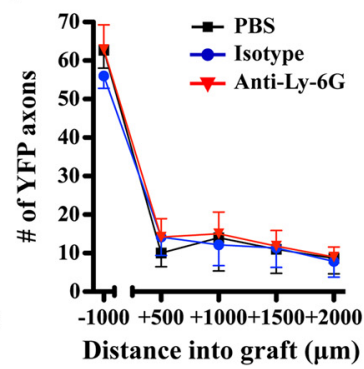

Figure 6. Neutrophil depletion following peripheral nerve injury decreases pain without interfering with axonal regeneration and functional recovery. $\boldsymbol{A}, \boldsymbol{B}$, Quantification of the number of neutrophils, characterized by their expression of the $L y-6 G(\boldsymbol{A})$ and (B) antigens and multilobed nucleus, in the sciatic nerve distal stump of mice treated with PBS, isotype control antibody, or partialsciaticnerve-ligated mice treated with either PBS, isotype control antibody, or anti-Ly-6G antibody ( $n=4-6$ mice/group) groups over a $42 \mathrm{~d}$ period ( $n=8-9$ mice/group; microcrush lesion model). $\boldsymbol{F}$, Quantification of the number of YFP-labeled axons at predetermined distances from the proximal host-graft interface following neutrophil depletion at $7 \mathrm{~d}$ after grafting $(n=4-6$ mice/group). ${ }^{* * *} p<0.001,{ }^{* *} p<0.01$, and ${ }^{*} p<0.05$ compared with PBS-treated mice. ${ }^{+t \dagger} p<0.001,{ }^{\dagger+} p<0.01$, and ${ }^{\dagger} p<$ 0.05 compared with mice treated with the isotype control antibody.

\section{Discussion}

The present study demonstrates that sciatic nerve injury induces a rapid production and release of IL- $1 \beta$ and TNF and causes infiltration of neutrophils and proinflammatory M1 monocytes/ macrophages into the distal stump. Mice lacking both IL-1R1 and TNFR1 had reduced neutrophil and M1 macrophage influx and reduced nociceptive hypersensitivity compared with wild-type littermates after injury. However, recovery of sciatic nerve function was impaired in IL- $1 \beta-$, TNF-, and IL- $1 \beta /$ TNF-ko mice. In addition, we found that neutrophil depletion, a strategy that alleviates neuropathic pain after sciatic nerve ligation, does not affect axonal regeneration and recovery of sciatic nerve function. Together, these results indicate that therapeutic approaches aimed at blocking neutrophil entry are likely to be more beneficial than neutralizing proinflammatory cytokines such as IL-1 and TNF in the treatment of neuropathic pain.

Activation of the innate immune response orchestrates a complex, tightly regulated cascade of events inducing production and processing of proinflammatory cytokines such as IL-1 and TNF. IL- $1 \alpha$ and IL- $1 \beta$ are synthesized as $31 \mathrm{kDa}$ precursor peptides that are cleaved by calpain and caspase-1, respectively, into 17 kDa mature cytokines (Dinarello, 2009; Gabay et al., 2010). Of the three cytokines investigated in this study, only the precursor form of IL- $1 \alpha$ was constitutively produced under normal conditions. However, many cell types, including neural cells constitu- 
tively produce pro-IL- $1 \alpha$ and pro-IL- $1 \beta$ (de Rivero Vaccari et al., 2008; Dinarello, 2009), but only the precursor form of IL- $1 \alpha$ is biologically active. Therefore, it is possible that dead and dying cells produced after traumatic injury may serve as a source of proinflammatory IL- $1 \alpha$. In support of this idea is a recent study by Chen et al. (2007) that showed that activation of IL-1R1 by IL- $1 \alpha$, but not IL- $1 \beta$, is absolutely required for the sterile inflammatory response triggered by necrotic cells and tissue (liver) injury.

Peripheral nerve injury resulted in increased in IL- $1 \beta$ mRNA expression in the sciatic nerve distal stump at early times after injury and this expression was significantly compromised in IL1R1- and MyD88-ko mice. However, the increase in IL-1 $\beta$ mRNA expression detected during the early phase after injury was not completely reduced in MyD88-ko mice and slightly lowered in MyD88-ko mice compared to IL-1R1-ko mice. These results indicate that in addition to IL-1R1 other receptors that signal via the MyD88 adaptor protein participate in the production of IL- $1 \beta$ in the injured peripheral nerve. Our recent finding that TLR2, a receptor that signals through MyD88 and responds to several endogenous molecules that are released in the environment of the injured peripheral nerve (for review, Pineau and Lacroix, 2009), plays an important role in the early expression of IL- $1 \beta$ mRNA supports this idea (Boivin et al., 2007). Thus, IL- $1 \alpha$, IL-1 $\beta$, and TNF appear to be initiators of inflammation after peripheral nerve injury.

Our results demonstrate that neutrophil infiltration is prevented in IL-1R1/TNFR1-ko mice in response to sciatic nerve injury. The importance of IL-1R1/MyD88 signaling for neutrophil infiltration was recently demonstrated in a number of animal models of injury, including brain abscess as well as lung, liver, and spinal cord injury (Chen et al., 2007; Gasse et al., 2007; Kielian et al., 2007; Pineau et al., 2010). However, our findings provide the report that neutrophil infiltration is more significantly impaired in the sciatic nerve distal stump of IL-1R1/TNFR1-ko mice ( $93 \%$ reduction) than MyD88-ko mice (60\% reduction), compared with their respective wild-type littermates at $1 \mathrm{~d}$ after lesion. These data indicate that both IL-1R1 and TNFR1 are important for neutrophil infiltration at the sites of nerve injury.

Neutrophils are one of the first cells recruited at sites of infection and injury. Mice deficient in IL-1R1 and TNFR show significant decreases in the number of neutrophils at the site of injury and are refractory to mechanical allodynia in the partial sciatic nerve ligation model. These findings indicate a critical role for IL-1 and TNF in the development and persistence of pain in various models (Verri et al., 2006; Scholz and Woolf, 2007; Watkins et al., 2007). Importantly, our results show that IL- $1 \beta$ and TNF not only modulate pain after neural injury, but also influence nerve repair and functional recovery. Thus, the findings reported here provide a framework for more targeted investigations into molecular mechanism of IL-1 and TNF signaling in modulation of neuropathic pain and nerve reparative processes.

Since certain subsets of monocytes/macrophages are necessary for neural repair after injury (Barrette et al., 2008; Kigerl et al., 2009), and considering the possible involvement of neutrophils in neuropathic pain (Austin and Moalem-Taylor, 2010), our study focused on the role of neutrophils in peripheral nerve regeneration and repair. Neutrophil depletion was achieved through repeated intravenous injections of the anti-Ly-6G (1A8) antibody. This depletion method has proven to be effective and more specific than depletion with the anti-Gr-1 (RB6-8C5) antibody, as the anti-Gr-1 antibody recognizes both the Ly- $6 \mathrm{G}$ and Ly- $6 \mathrm{C}$ antigens, and because the Ly-6C antigen is expressed in neutrophils as well as in dendritic cells and certain subsets of monocytes and lymphocytes (Daley et al., 2008). Neutrophildepletion experiments support the earlier finding of Perkins and Tracey that show that neutrophils contribute to thermal hypersensitivity after peripheral nerve injury in rats (Austin and Moalem-Taylor, 2010), and provide additional information that neutrophils influence mechanical hypersensitivity. Importantly, we found that the extent of axonal regeneration in sciatic nerve distal stumps and functional recovery (SFI) showed no significant difference between anti-Ly-6G-treated and control mice, indicating that neutrophils are not essential for nerve regeneration. Therefore, we hypothesize that therapeutic strategies that block or reduce neutrophil recruitment after peripheral nerve injury will result in better functional outcomes than antiproinflammatory cytokine therapies.

The pharmacological treatment of neuropathic pain has not advanced and there are no approved therapies to improve the long-term prognosis of peripheral nerve injury. One challenge is to design novel therapeutics that reduce pain without interference of nerve regeneration and reparative processes. Our study demonstrates that neutrophils play a pivotal role in the genesis of neuropathic pain and do not contribute significantly to peripheral nerve regeneration and functional recovery. Thus, the depletion of neutrophils and the dynamic regulation of other types of immune cells at the site of injury offer potential for new therapeutic approaches to inhibit pain without interference of regenerative and functional improvement.

\section{References}

Audoy-Rémus J, Richard JF, Soulet D, Zhou H, Kubes P, Vallières L (2008) Rod-shaped monocytes patrol the brain vasculature and give rise to perivascular macrophages under the influence of proinflammatory cytokines and angiopoietin-2. J Neurosci 28:10187-10199.

Austin PJ, Moalem-Taylor G (2010) The neuro-immune balance in neuropathic pain: involvement of inflammatory immune cells, immune-like glial cells and cytokines. J Neuroimmunol 229:26-50.

Barrette B, Hébert MA, Filali M, Lafortune K, Vallières N, Gowing G, Julien JP, Lacroix S (2008) Requirement of myeloid cells for axon regeneration. J Neurosci 28:9363-9376.

Boivin A, Pineau I, Barrette B, Filali M, Vallières N, Rivest S, Lacroix S (2007) Toll-like receptor signaling is critical for Wallerian degeneration and functional recovery after peripheral nerve injury. J Neurosci 27:12565-12576

Chen CJ, Kono H, Golenbock D, Reed G, Akira S, Rock KL (2007) Identification of a key pathway required for the sterile inflammatory response triggered by dying cells. Nat Med 13:851-856.

Daley JM, Thomay AA, Connolly MD, Reichner JS, Albina JE (2008) Use of Ly6G-specific monoclonal antibody to deplete neutrophils in mice. J Leukoc Biol 83:64-70.

de Rivero Vaccari JP, Lotocki G, Marcillo AE, Dietrich WD, Keane RW (2008) A molecular platform in neurons regulates inflammation after spinal cord injury. J Neurosci 28:3404-3414.

Dinarello CA (2009) Immunological and inflammatory functions of the interleukin-1 family. Annu Rev Immunol 27:519-550.

Gabay C, Lamacchia C, Palmer G (2010) IL-1 pathways in inflammation and human diseases. Nat Rev Rheumatol 6:232-241.

Gasse P, Mary C, Guenon I, Noulin N, Charron S, Schnyder-Candrian S, Schnyder B, Akira S, Quesniaux VF, Lagente V, Ryffel B, Couillin I (2007) IL-1R1/MyD88 signaling and the inflammasome are essential in pulmonary inflammation and fibrosis in mice. J Clin Invest 117:3786-3799.

Gordon S, Taylor PR (2005) Monocyte and macrophage heterogeneity. Nat Rev Immunol 5:953-964.

Henderson RB, Hobbs JA, Mathies M, Hogg N (2003) Rapid recruitment of inflammatory monocytes is independent of neutrophil migration. Blood 102:328-335.

Horai R, Asano M, Sudo K, Kanuka H, Suzuki M, Nishihara M, Takahashi M, Iwakura Y (1998) Production of mice deficient in genes for interleukin (IL)-1alpha, IL-1beta, IL-1alpha/beta, and IL-1 receptor antagonist 
shows that IL-1beta is crucial in turpentine-induced fever development and glucocorticoid secretion. J Exp Med 187:1463-1475.

Inserra MM, Bloch DA, Terris DJ (1998) Functional indices for sciatic, peroneal, and posterior tibial nerve lesions in the mouse. Microsurgery 18:119-124.

Kielian T, Phulwani NK, Esen N, Syed MM, Haney AC, McCastlain K, Johnson J (2007) MyD88-dependent signals are essential for the host immune response in experimental brain abscess. J Immunol 178:4528-4537.

Kigerl KA, Gensel JC, Ankeny DP, Alexander JK, Donnelly DJ, Popovich PG (2009) Identification of two distinct macrophage subsets with divergent effects causing either neurotoxicity or regeneration in the injured mouse spinal cord. J Neurosci 29:13435-13444.

Liu T, van Rooijen N, Tracey DJ (2000) Depletion of macrophages reduces axonal degeneration and hyperalgesia following nerve injury. Pain 86:25-32.

Malmberg AB, Basbaum AI (1998) Partial sciatic nerve injury in the mouse as a model of neuropathic pain: behavioral and neuroanatomical correlates. Pain 76:215-222.

Marchand F, Perretti M, McMahon SB (2005) Role of the immune system in chronic pain. Nat Rev Neurosci 6:521-532.

Moalem G, Xu K, Yu L (2004) Tlymphocytes play a role in neuropathic pain following peripheral nerve injury in rats. Neuroscience 129:767-777.

Nahrendorf M, Swirski FK, Aikawa E, Stangenberg L, Wurdinger T, Figueiredo JL, Libby P, Weissleder R, Pittet MJ (2007) The healing myocardium sequentially mobilizes two monocyte subsets with divergent and complementary functions. J Exp Med 204:3037-3047.

Perkins NM, Tracey DJ (2000) Hyperalgesia due to nerve injury: role of neutrophils. Neuroscience 101:745-757.

Pineau I, Lacroix S (2009) Endogenous signals initiating inflammation in the injured nervous system. Glia 57:351-361.

Pineau I, Sun L, Bastien D, Lacroix S (2010) Astrocytes initiate inflammation in the injured mouse spinal cord by promoting the entry of neutrophils and inflammatory monocytes in an IL-1 receptor/MyD88-dependent fashion. Brain Behav Immun 24:540-553.

Scholz J, Woolf CJ (2007) The neuropathic pain triad: neurons, immune cells and glia. Nat Neurosci 10:1361-1368.

Seltzer Z, Dubner R, Shir Y (1990) A novel behavioral model of neuropathic pain disorders produced in rats by partial sciatic nerve injury. Pain 43:205-218.

Shubayev VI, Myers RR (2000) Upregulation and interaction of TNFalpha and gelatinases A and B in painful peripheral nerve injury. Brain Res 855:83-89.

Stirling DP, Yong VW (2008) Dynamics of the inflammatory response after murine spinal cord injury revealed by flow cytometry. J Neurosci Res 86:1944-1958.

Tsou CL, Peters W, Si Y, Slaymaker S, Aslanian AM, Weisberg SP, Mack M, Charo IF (2007) Critical roles for CCR2 and MCP-3 in monocyte mobilization from bone marrow and recruitment to inflammatory sites. J Clin Invest 117:902-909.

Turrin NP, Rivest S (2006) Tumor necrosis factor alpha but not interleukin 1 beta mediates neuroprotection in response to acute nitric oxide excitotoxicity. J Neurosci 26:143-151.

Verri WA Jr, Cunha TM, Parada CA, Poole S, Cunha FQ, Ferreira SH (2006) Hypernociceptive role of cytokines and chemokines: targets for analgesic drug development? Pharmacol Ther 112:116-138.

Watkins LR, Maier SF (2002) Beyond neurons: evidence that immune and glial cells contribute to pathological pain states. Physiol Rev 82:981-1011.

Watkins LR, Hutchinson MR, Milligan ED, Maier SF (2007) "Listening" and "talking" to neurons: implications of immune activation for pain control and increasing the efficacy of opioids. Brain Res Rev 56:148-169.

Zhang J, Shi XQ, Echeverry S, Mogil JS, De Koninck Y, Rivest S (2007) Expression of CCR2 in both resident and bone marrow-derived microglia plays a critical role in neuropathic pain. J Neurosci 27:12396-12406. 